\title{
Alternative Metabolic Strategies are Employed by Endurance Runners of Different Body Sizes; Implications for Human Evolution
}

\section{Adaptive Human Behaviour and Physiology Special Issue}

\author{
Daniel P. Longman ${ }^{1}$ D . Viviane Merzbach ${ }^{2}$ (D) Jorge Marques Pinto ${ }^{2}$ (D) \\ Laura Hope Atkinson ${ }^{3}$ (D) Jonathan C. K. Wells ${ }^{4}$ (D) Dan Gordon ${ }^{2}$ (D) . \\ Jay T. Stock $\mathbf{k}^{3,5}$ (D)
}

Received: 17 September 2021 / Revised: 16 December 2021 / Accepted: 17 December 2021 / Published online: 10 January 2022

(c) The Author(s) 2022

\begin{abstract}
Objective A suite of adaptations facilitating endurance running (ER) evolved within the hominin lineage. This may have improved our ability to reach scavenging sites before competitors, or to hunt prey over long distances. Running economy (RE) is a key determinant of endurance running performance, and depends largely on the magnitude of force required to support body mass. However, numerous environmental factors influence body mass, thereby significantly affecting RE. This study tested the hypothesis that alternative metabolic strategies may have emerged to enable ER in individuals with larger body mass and poor RE.

Methods A cohort of male $(n=25)$ and female $(n=19)$ ultra-endurance runners completed submaximal and exhaustive treadmill protocols to determine RE, and $\mathrm{VO}_{2 \mathrm{Max}}$.

Results Body mass was positively associated with sub-maximal oxygen consumption at both LT1 (male $r=0.66, p<0.001$; female LT1 $r=0.23, p=0.177$ ) and LT2 (male $r=0.59, p=0.001$; female $r=0.23, p=0.183$ ) and also with $\mathrm{VO}_{2 \mathrm{Max}}$ (male $r=0.60, p=0.001$; female $r=0.41, p=0.046$ ). Additionally, sub-maximal oxygen consumption varied positively with $\mathrm{VO}_{2 \mathrm{Max}}$ in both male (LT1 $r=0.54, p=0.003$; LT2 $r=0.77, p<0.001$ ) and female athletes (LT1 $r=0.88, p<0.001$; LT2 $r=0.92$, $p<0.001)$.

Conclusions The results suggest that, while individuals with low mass and good RE can glide economically as they run, larger individuals can compensate for the negative effects their mass has on RE by increasing their capacity to consume oxygen. The elevated energy expenditure of this low-economy high-energy turnover
\end{abstract}

Dan Gordon and Jay T. Stock are joint senior authors.

Extended author information available on the last page of the article 
approach to ER may bring costs associated with energy diversion away from other physiological processes, however.

Keywords Evolution · Endurance running · Running economy · Energetics

\section{Introduction}

\section{Humans as Endurance Runners}

Humans are unique amongst primates in being able to run distances of multiple kilometres using aerobic metabolism (Carrier, 1984). This ability emerged during evolution of the hominin lineage. Although anatomically modern humans are poor sprinters compared to most quadrupeds, amateur human runners are typically able to sustain speeds of $5 \mathrm{~m} / \mathrm{s}$, which compares favourably with specialised quadrupedal cursors. For example, a $65 \mathrm{~kg}$ dog would be expected to have a trot-gallop transition speed of $3.8 \mathrm{~m} / \mathrm{s}$, and could then only gallop at around $7.8 \mathrm{~m} / \mathrm{s}$ for up to 15 -minutes under ideal conditions (Heglund \& Taylor, 1988; Lieberman et al., 2006). A similar comparison can be made with horses, despite their selective breeding for running ability. Horses can maintain a gallop speed of $8.9 \mathrm{~m} / \mathrm{s}$ for $10 \mathrm{~km}$ (much faster than humans), but are limited to a canter at around $5.8 \mathrm{~m} / \mathrm{s}$ for distances around $20 \mathrm{~km} /$ day (beatable by well-trained humans) (Lieberman \& Bramble, 2007; Minetti, 2003). This capability allows human runners to comfortably cover daily distances in excess of $10 \mathrm{~km}$, which is comparable with the scavenging and hunting of hunting dogs and hyenas (Lieberman et al., 2006).

Scavenging and hunting may have provided the primary selective pressure leading to the evolution of endurance running, which likely emerged in the hominin lineage after our divergence from our last common ancestor with the chimpanzee (Lieberman et al., 2006). The ability to run long distances to hunt prey over long distances using methods such as persistence hunting (the pursuit of prey to the point of prey exhaustion / hyperthermia), may have improved the chances of acquiring meat (Bunn, 2001; Lieberman et al., 2006; Longman et al., 2015).

A suite of evolved features facilitate endurance running (Bramble \& Lieberman, 2004; Lieberman, 2010, 2012a, b, 2015). These adaptations may be considered relative to four main demands posed by endurance running; energetics, strength, stabilisation and thermoregulation (Bramble \& Lieberman, 2004). Considering energetics, humans exhibit a range of anatomical traits enhancing running economy (RE).

First, we are unique amongst primates due to the large number of long spring-like tendons allowing the energetically economic generation of force. Running employs a mass-spring mechanism, which handles the exchange between gravitational potential energy and kinetic energy differently to the walking gait. Energy is stored during the initial breaking when the foot lands, and released during the subsequent propulsive phase. The multitude of spring-like tendons (for example the Achilles tendon) that developed during the hominin lineage allows for the efficient storage and release of energy during running. While these tendons have little effect during walking, they 
may reduce the energetic cost of running by around 50\%. Tendons found in the longitudinal arch of the foot confer further energetic gains, returning almost a fifth of the energy generated during each stride (Ker, 1987).

Second, humans may gain further energetic efficiency whilst running by varying stride length. In contrast to quadrupeds, humans tend to increase running speed by increasing stride length, rather than by increasing stride rate [discussed in (Bramble \& Lieberman, 2004)]. Thirdly, the lower limb elongation characterising the hominin lineage allows for not only a longer stride length, but also increased ground contact time, which reduces the metabolic cost of running (Roberts et al., 1998). Increasing ground contact time decreases the required rate of ground force application, reducing the energetic cost. As a result, the energy expenditure of running animals is an inverse function of ground contact time [discussed in (Wright \& Weyand, 2001)]. The low resultant stride frequency of humans may also offset the drawback of long legs - an increased limb mass moment of inertia. This cost is also reduced by the compact feet of humans, which are smaller than those of Chimpanzees relative to body mass (Zihlman \& Brunker, 1979).

The importance of energy in the process of evolution has long been recognised. Building upon the work of early proponents of the central role played by energy homeostasis (Boltzmann, 1886; Lodge, 1906), Lotka wrote that “...the fundamental object of contention in the life-struggle, in the evolution of the organic world, is available energy" (Lotka, 1922). The effects of the powerful influence of energy on our evolutionary journey are visible throughout our biology and function. For example, the adoption and persistence of bipedalism - considered a defining characteristic of human evolution (Dart, 1925; Napier, 1967; Rodman \& McHenry, 1980) and instrumental in the development of endurance running ability - is understood to be driven by gains in locomotor efficiency serving to reduce the energetic cost of calorie acquisition (Cerling et al., 2010; Haile-Selassie, 2001; Pontzer et al., 2009; Senut \& Pickford, 2004; Sockol et al., 2007). As the cooler and drier climate of the late Miocene is thought to have made food patches more sparse (Cerling et al., 1997), more economical locomotion allowed early hominins to travel greater distances in search of food (Rodman \& McHenry, 1980).

\section{Influence of Environmental Factors on Running Economy}

RE is a key determinant of endurance running performance (di Prampero, 2003; Ingham et al., 2008; Joyner, 1991; Lucia et al., 2002; McLaughlin et al., 2010). While a range of physiological factors influence running economy [including mechanical efficiency (Cavanagh et al., 1977; Williams \& Cavanagh, 1985), muscles' ability to store and release elastic energy by increasing lower-body stiffness (Dalleau et al., 1998) and intramuscular metabolic adaptations including increased mitochondria and oxidative enzymes (Holloszy et al., 1977)], RE depends largely on the magnitude of force generation required to support body mass. This force generation accounts for up to $74 \%$ of the total energetic cost of running (Ackerman \& Seipel, 2016; Epstein et al., 1987; Farley \& McMahon, 1992; Kram \& Taylor, 1990; 
Maldonado-Martin \& Padilla, 2002; Taylor et al., 1980; Teunissen et al., 2007). Body mass is therefore an important driver of RE (Anderson, 1996; Pate et al., 1992).

Body mass is affected by a range of environmental factors. Considering climate, Bergmann's rule describes patterns of variation both within and across species relative to the temperature of their environment, with endotherms expected to be larger in colder environments (Bergmann, 1847). Recent research combining comprehensive palaeontological data with climate models demonstrates that temperature is the only environmental variable to correspond with variation in body size across the last one million years of hominin evolution (Will et al., 2021). While earlier PlioPleistocene increases in body size may have been driven by early hominin migrations into more variable environments and through changes in the hominin dietary niche (Will et al., 2017; Will \& Stock, 2015), the recent analyses suggest that that thermal stress was the primary driver of variation in hominin body size within the genus Homo (Will et al., 2021). Modern humans also show patterns of phenotypic variation consistent with Bergmann's rule Crognier 1981; Foster \& Collard, 2013; Hiernaux, 1968; Hiernaux \& Fromont, 1976; Holliday, 1997a, b; Holliday \& Trinkaus, 1991; Ruff, 1994; Stinson, 1990; Tilkens et al., 2007; Trinkaus, 1981). Early work by Roberts identified a negative relationship between mean annual temperature and body mass in humans (Roberts, 1953). The trends at higher latitudes have been reported to be diminishing in strength (Katzmarzyk \& Leonard, 1998), and the pattern is only observable with a sufficiently large temperature (or latitude) range (Foster \& Collard, 2013). Recent analyses of the relationship between body composition and environment found that lean mass, a metabolically expensive tissue, increases with food supply and decreases with a marker of food insecurity and infectious disease. In contrast, adiposity increases with temperature volatility, an indicator of the risk of infectious disease (Wells et al., 2019). These findings suggest that the relationship between climate and morphology extend beyond body mass, as predicted by Bergmann's Rule. The extent to which ecogeographic variation in human body-size is driven by natural selection or plasticity remains unknown, but it is likely that developmental plasticity is a key component of phenotypic variation in body size and proportions among homeotherms (Rogers, 2003; Serrat et al., 2008; Te Velde et al., 2003).

\section{Body Mass and Metabolic Approaches to Endurance Running}

It is clear from the sports science literature that excellent RE is necessary for success as an elite endurance runner (di Prampero, 2003; Ingham et al., 2008; Joyner, 1991; Lucia et al., 2002; McLaughlin et al., 2010; Shaw et al., 2015). However, the aim of ancestral endurance running was not to be the fastest, but rather, to be able to run well enough to hunt or scavenge successfully in order to survive. As previously discussed, numerous environmental factors influence adult body mass, potentially through both selection and plastic responses during development, which in turn significantly affects RE. As the ability to run long 
distances would have been advantageous irrespective of body mass, it is possible that alternative metabolic strategies emerged, facilitating endurance running in individuals with larger body masses.

Here, we seek to test the hypothesis that, while individuals with low mass can perform endurance running economically, heavier runners may be able to compensate for their low economy by increasing their maximal capacity to consume oxygen $\left(\mathrm{VO}_{2 \mathrm{Max}}\right)$ and meet their elevated energetic costs of running. More specifically, in a cohort of successful ultra-endurance runners, we predict an inverse correlation between $\mathrm{RE}$ and $\mathrm{VO}_{2 \mathrm{Max}}$.

Previous work has considered the relationship of $\mathrm{RE}$ and $\mathrm{VO}_{2 \mathrm{Max}}$. Positive relationships have been reported from several studies with relatively small (Fletcher et al., 2009; Morgan \& Daniels, 1994; Pate et al., 1992), and more recently in a larger cohort of 168 trained distance runners (males $r=0.26$, female $r=0.25$ ) (Shaw et al., 2015).

\section{Methods}

\section{Study Design}

Following local institutional ethical approval (Faculty Research and Ethics Panel, Anglia Ruskin University), $n=46$ ultra-endurance runners (27 males, 19 females) agreed to participate and gave their written informed consent. All runners had previously competed in one of four multi-stage ultra-marathon events in 2016/17 (Rovaniemi150 (Finland), Jungle Ultra (Peru), Al Andalus Ultimate Trail (Spain) and Everest Trail Race (Nepal)) to be eligible for this study. This investigation stems from a wider research theme using contemporary sports as a tool to examine evolutionary theory Longman et al., 2015, 2018, 2019, 2020, 2021; Longman et al., 2017a, b). More specifically, the current study is part of the ADaPt Project, which is developing the use of ultra-endurance challenges as experimental scenarios to study trade-offs relating to life history theory (Longman et al., 2017a, b).

All participants attended the Cambridge Centre for Sport and Exercise Sciences on one occasion for the assessment of isokinetic knee extensors and flexors peak torques across a range of angular speeds during concentric and eccentric loading for both legs. Furthermore, all participants $(n=44,2$ male participants had to be excluded: 1 due to medical reasons, 1 due to equipment failure) performed an incremental treadmill test for the evaluation of running economy, submaximal blood lactate responses and the assessment of maximal oxygen uptake $\left(\dot{\mathrm{V}}_{2 \max }\right)$. Body mass $(\mathrm{kg})$ was measured using electronic scales (Seca, Hamburg, Germany) and body height $(\mathrm{cm})$ was determined using a stadiometer (Seca, Hamburg, Germany) prior to all testing. 


\section{Submaximal Treadmill Protocol}

Each participant completed a submaximal incremental speed-based protocol for the determination of lactate threshold 1 (LT1), lactate turn-point 2 (LT2), and running economy (RE) (Gordon et al., 2017). The starting speed was selected on an individual basis to coincide with a speed that the participant would normally warm-up at, and thereafter was increased by $1 \mathrm{~km} \bullet \mathrm{h}^{-1}$ every $3 \mathrm{~min}$. Throughout the test, the gradient was kept constant at $1 \%$. After each 3-minute increment, there was a 1-minute break where upon the participant was asked to stand astride of the treadmill to facilitate the collection of a capillary fingertip blood sample $(20 \mu \mathrm{L})$ for the immediate determination of blood lactate concentrations. Once the sample was collected, the participants were asked to ease themselves back onto the treadmill and complete the remaining time of the 1-minute recovery at walking pace $\left(4 \mathrm{~km} \cdot \mathrm{h}^{-1}\right)$. Throughout the test, individual blood lactate responses $\left(\mathrm{mmol} \bullet \mathrm{L}^{-1}\right)$ were plotted against exercise intensity $\left(\mathrm{km} \bullet \mathrm{h}^{-1}\right)$ for the determination of lactate LT1 and LT2. Identification of LT1 was based on the first initial rise above baseline, whilst LT2 was the sudden and sustained increase in blood lactate, determined through visual inspection of the blood lactate curve (Bourdon, 2000; Gordon et al., 2017). Two physiologists present in the laboratory independently validated both LT1 and LT2. The test was terminated once the participant had reached LT2. Gas exchange responses were recorded throughout all trials on a breath-by-breath basis with a pre-calibrated metabolic cart (MetaLyzer 3B-R2, Cortex Ltd, Germany) and HR responses were tracked using a telemetric system (T31 heart rate strap, Polar, Kempele, Finland). Oxygen consumption at LT1 and LT2 was used to provide the measure of RE used in subsequent analyses.

\section{$\mathrm{VO}_{2 \max }$ Protocol}

Upon completion of the submaximal treadmill protocol and following a 7-minute recovery, each participant was asked to complete an incremental gradientbased treadmill test to volitional exhaustion. The running speed was based on the speed at which LT2 occurred in the previous protocol and kept constant throughout. Every minute, the gradient was increased by $1 \%$ (starting at 1\%) until volitional exhaustion was reached, or when the participant was unable to maintain a predetermined position at the front of the treadmill. Verbal encouragement was provided towards the end of the test to facilitate a maximal effort of the participant. Immediately after completion of the $\dot{\mathrm{VO}}_{2 \max }$ test, a capillary blood sample $(20 \mu \mathrm{L})$ was collected for the determination of post-exercise blood lactate and glucose concentrations. Throughout the trial, expired air was recorded on a breath-by-breath basis and HR responses were documented using a telemetric system.

For both treadmill protocols, participants wore a harness connected to an emergency stop system of the treadmill for safety purposes. 


\section{Blood Lactate and Glucose Analysis}

Capillary blood samples $(20 \mu \mathrm{L})$ for the determination of blood lactate and glucose were collected from the fingertip. For each blood sample, the fingertip was pierced with a single-use lancet device system (ACCU-CHEK Safe-T-Pro Plus). The blood was drawn into an end-to-end haemolysed micro-capillary and placed into a pre-filled (with haemolysing solution) sample test tube $(2 \mathrm{~mL})$. To prepare the sample for immediate measurement with a lactate and glucose analyser (Biosen C-Line, EKF-diagnostic, Germany), the test tube was gently agitated until a uniform solution was produced. The analyser was set to self-calibrate every 60 min according to the manufacturer's instructions.

\section{Pulmonary Gas Exchange Responses}

Expired air was recorded for the assessment of pulmonary gas exchange responses. Participants wore a facemask secured with headgear (7600 Face Mask with Headgear, Hans Rudolph, USA) where the size of the mask was selected so that a seal could be achieved. A low-resistance volume transducer and capillary sample line for gases were secured to the facemask with both connected to an online metabolic cart (MetaLyzer 3B-R2, Cortex Ltd, Germany) which allowed for breath-by-breath analysis. Through the sample line, $\mathrm{O}_{2}$ and $\mathrm{CO}_{2}$ were drawn off at a rate of $60 \mathrm{~mL} \cdot \mathrm{min}^{-1}$ to determine expired gas concentrations. To align gas concentrations and respiratory responses, custom metabolic cart software (MetaSoft Studio V4.60, Cortex Ltd, Germany) was used to display breathby-breath gas exchange variables (volume of oxygen $\left(\mathrm{V}_{2}\right)$, volume of carbon dioxide $\left(\dot{\mathrm{VCO}}_{2}\right)$, minute ventilation $(\dot{\mathrm{VE}})$, respiratory exchange ratio (RER)). According to the manufacturer's specifications, the metabolic cart was calibrated for volume, flow, and gas concentrations prior to each trial. Anglia Ruskin University have previously achieved a $3.7 \%$ internal coefficient of variation for this technique.

\section{Statistics}

SPSS v27 was used for all analyses, with a significance benchmark of 0.05 . Independent samples t-tests were used to compare male and female descriptive statistics. Correlations between body mass, $\mathrm{RE}$ and $\mathrm{VO}_{2 \mathrm{Max}}$ were evaluated using Pearson's Product Moment Correlations. Scatter plots were made to visualize the relationship between variables. Finally, a multiple linear regression model was used. 


\section{Results}

\section{Descriptive Statistics}

As expected, the cohort exhibited sexual dimorphism. Males were 17.7 (95\% CI $12.0,22.5) \mathrm{kg}$ heavier, $14.6(95 \%$ CI $11.2,19.0) \mathrm{cm}$ taller, $1.0(95 \%$ CI $0.3,1.7)$ $\mathrm{km} / \mathrm{h}$ faster at LT1, $1.2(95 \%$ CI $0.3,2.2) \mathrm{km} / \mathrm{h}$ faster at LT2 and had a $\mathrm{VO}_{2 \mathrm{Max}}$ $4.4(95 \%$ CI $0.8,8.0) \mathrm{ml} / \mathrm{kg} / \mathrm{min}$ larger. Males were also 5.4 (95\% CI 0.4, 10.4) years older. There were no significant sex differences in oxygen consumption at either LT1, LT2, or between oxygen consumption at LT1 or LT2 as a percentage of $\mathrm{VO}_{2 \mathrm{Max}}$. A description of the male and female cohorts is given in Table 1.

\section{Body Mass, $\mathrm{RE}$ and $\mathrm{VO}_{2 \mathrm{Max}}$}

Regression analysis was performed to analyse the relationship between body mass and oxygen consumption at LT1 and LT2.

At LT1, a significant positive correlation was observed in male $(\mathrm{n}=25, \mathrm{r}=0.66$, $p<0.001$, 1-tailed; standardized $95 \%$ CI, 0.012 to 0.034 ) and a positive trend was seen in female athletes $(\mathrm{n}=18, \mathrm{r}=0.23, p=0.177,1$-tailed; standardized $95 \% \mathrm{CI}$, -0.013 to 0.034$)$. At LT2, a positive correlation was observed in male $(\mathrm{n}=25, \mathrm{r}=$ $0.59, p=0.001$, 1-tailed; standardized $95 \% \mathrm{CI}, 0.012$ to 0.047 ) and female athletes ( $\mathrm{n}=18, \mathrm{r}=0.23, p=0.183$, 1-tailed; standardized $95 \% \mathrm{CI},-0.015$ to 0.039 ). See Fig. 1.

Regression analysis revealed a significant positive correlation between body mass and $\mathrm{VO}_{2 \mathrm{Max}}$ in both male athletes $(\mathrm{n}=25, \mathrm{r}=0.60, p=0.001,1$-tailed; standardized $95 \% \mathrm{CI}, 0.016$ to 0.062$)$ and female athletes $(\mathrm{n}=18, \mathrm{r}=0.41, p=0.046,1$-tailed; standardized 95\% CI, -0.004 to 0.047). See Fig. 2.

\section{$\mathrm{VO}_{2 \mathrm{Max}}$ and RE}

Regression analysis revealed significant positive correlations between $\mathrm{VO}_{2 \mathrm{Max}}$ and RE in both male and female athletes. At LT1 there was a significant positive correlation with both male ( $\mathrm{n}=25, \mathrm{r}=0.54, p=0.003,95 \%$ CI 0.332 to 1.722$)$ and female athletes $(\mathrm{n}=18, r=0.88, p<0.001$, 95\% CI 0.681 to 1.230$)$. Similarly, at LT2 there was a significant positive correlation with both male $(\mathrm{n}=25, \mathrm{r}=0.77, p$ $<0.001,95 \%$ CI 0.635 to 1.342$)$ and female athletes $(\mathrm{n}=18, r=0.92, p<0.001$, 95\% CI 0.677 to 1.067$)$. See Fig. 3.

A partial correlation was run to determine the relationship between $\mathrm{VO}_{2 \mathrm{Max}}$ and running economy whilst controlling for body mass. This is necessary as both variables are expressed relative to body mass, creating a common denominator which can lead to spurious correlations (Atkinson et al., 2003). Both sexes displayed a significant positive correlation between $\mathrm{VO}_{2 \mathrm{Max}}(\mathrm{ml} / \mathrm{kg} / \mathrm{min})$ and $\mathrm{RE}(\mathrm{ml} / \mathrm{kg} / \mathrm{min})$. At LT1 the correlation was significant in males $(r(22)=0.420, p=0.041)$ but not females $(r(15)=0.138, p$ $=0.598)$ while at LT2 the correlation was significant in both males $(r(22)=0.765, p$ 


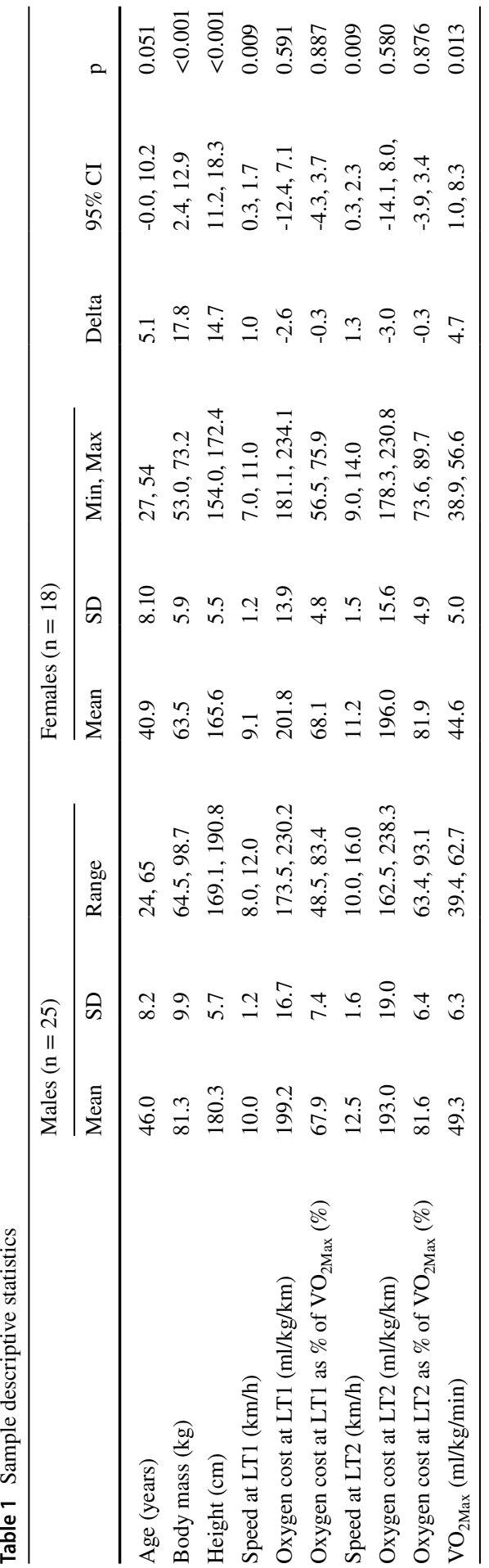




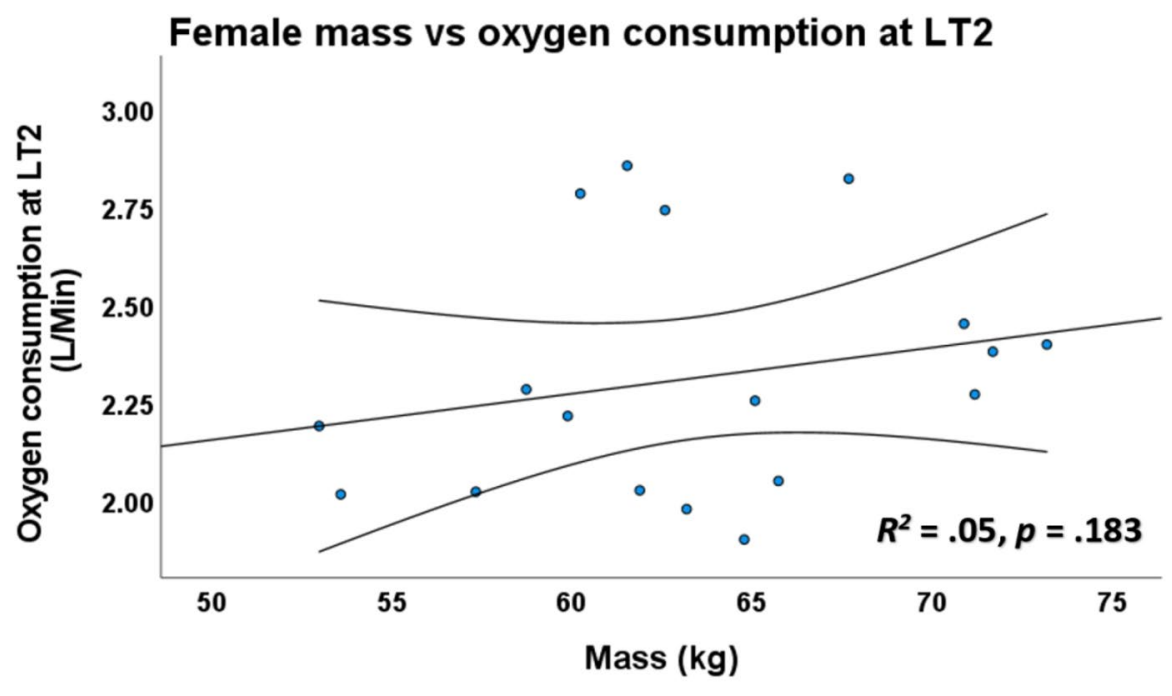

Male mass vs oxygen consumption at LT2

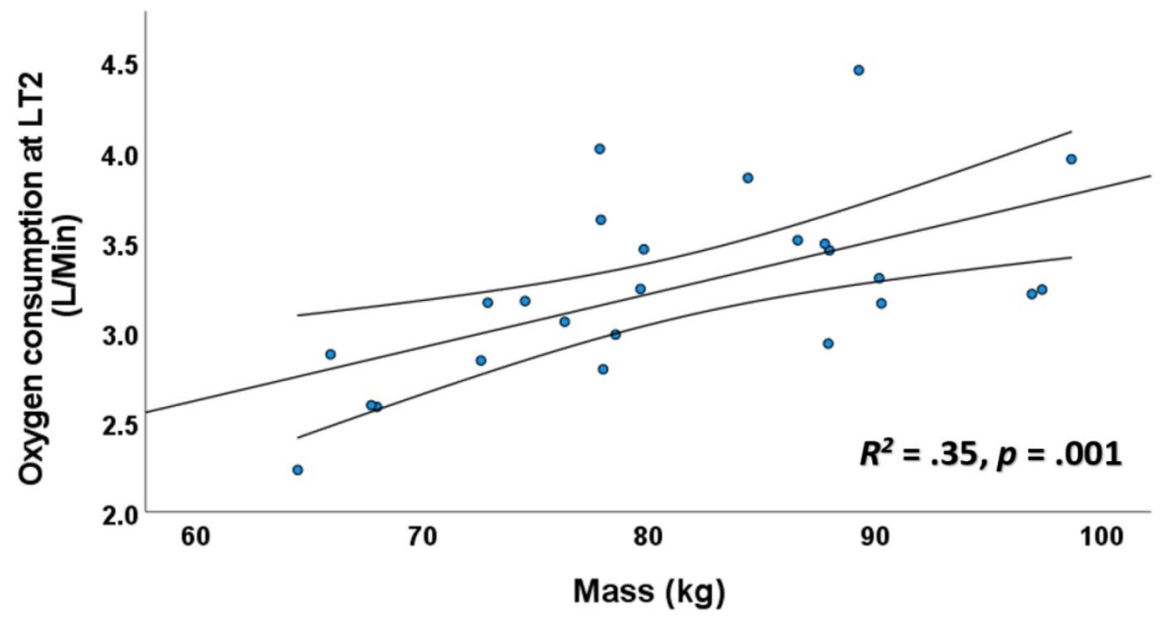

Fig. 1 Scatter plot of body mass and oxygen consumption at LT2 for male and female participants (95\% confidence interval)

$<0.001)$ and females $(r(15)=0.904, p<0.001)$. Zero-order correlations showed that these correlations persisted, indicating that body mass had little influence in controlling for the relationship between $\mathrm{VO}_{2 \mathrm{Max}}$ and $\mathrm{RE}$. 

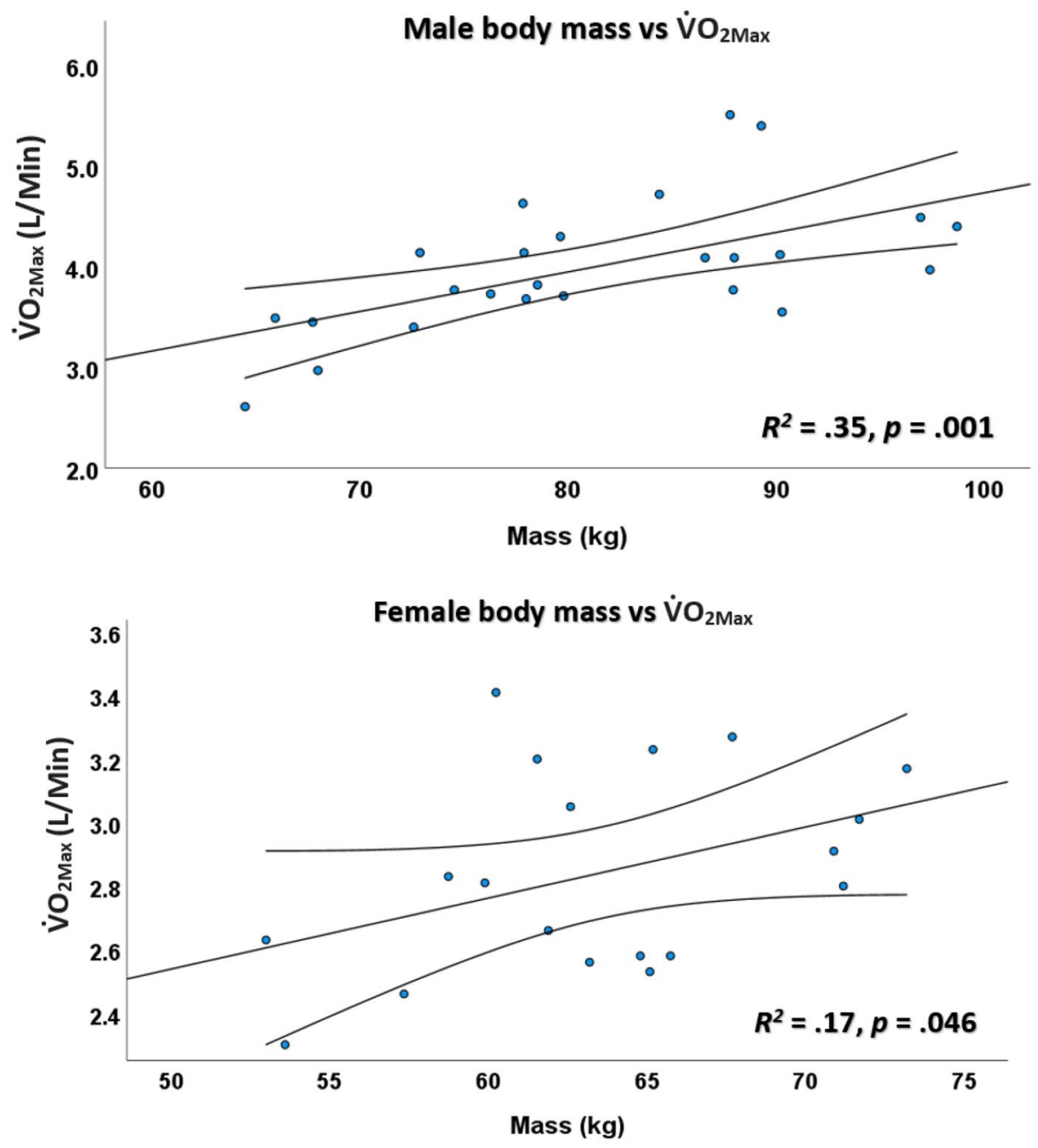

Fig. 2 Scatter plot of body mass and $\mathrm{VO}_{2 \mathrm{Max}}$ for female and male participants (95\% confidence intervals)

\section{Discussion}

Body mass was found to vary negatively with RE in both male and female athletes (as observed by positive correlations between mass and oxygen consumption at both LT1 and LT2 in male and female athletes). This was consistent with the existing literature (Anderson, 1996; Pate et al., 1992). Other variables that might be expected to contribute to variation in RE include mechanical efficiency (Cavanagh et al., 1977; Williams \& Cavanagh, 1985), the muscles' ability to store and release elastic energy by increasing lower-body stiffness (Dalleau et al., 1998) as well as intramuscular metabolic adaptations, which include increased mitochondria and oxidative enzymes (Holloszy et al., 1977). Further, this study 
Fig. 3 Scatter plot of RE at LT1 \& LT2 and $\mathrm{VO}_{2 \mathrm{Max}}$ for female and male participants (95\% confidence intervals)

identified an inverse relationship between $\mathrm{VO}_{2 \mathrm{Max}}$ and $\mathrm{RE}$. This was observed as a positive correlation between $\mathrm{VO}_{2 \mathrm{Max}}$ and oxygen consumption at both LT1 and LT2 in male and female athletes. This inverse relationship has previously been reported in elite cyclists (Lucia et al., 2002; Santalla et al., 2009) as well as trained endurance runners (Fletcher et al., 2009; Morgan \& Daniels, 1994; Pate et al., 1992; Shaw et al., 2015), leading to the suggestion that competitive runners may compensate for a lower $\mathrm{VO}_{2 \mathrm{Max}}$ with superior $\mathrm{RE}$. To our knowledge, this is the first study demonstrating a negative association between $\mathrm{VO}_{2 \mathrm{Max}}$ and $\mathrm{RE}$ in ultra-endurance athletes.

Prehistoric hominin foragers engaged in persistence hunting differ from modern-day endurance athletes in that they did not strive to be the fastest. Instead, the challenge was to be able to run well enough to enhance survival by scavenging and/or hunting to access nutrition. They did so using bodies of variable mass and proportions, shaped by environmental stress such as temperature, with larger body sizes typically found in colder, more open environments with greater frequencies of large game (Will et al., 2021). Individuals with good RE and lower body mass, common in warmer environments, could likely glide economically as they ran. In contrast, our results suggest that larger individuals typical of hominins living in colder environments may be able to compensate for the negative effects that their mass has on RE by increasing their capacity to consume oxygen. This may allow them to power their way to calories. The findings reported in this study, which recruited a cohort of athletes who have successfully completed an ultramarathon (150-300 km in distance), are thereby suggestive of the existence of alternative metabolic approaches to performing endurance running. These different strategies allow humans, irrespective of their adult body size, to occupy the same behavioural niche of endurance running as a means of acquiring calories.

The elevated energy expenditure associated with the low-economy high-energy turnover approach may bring costs, however. Recent work has identified preliminary evidence suggestive of an apparent limit to daily energy expenditure, with daily energy expenditure being homeostatically maintained within a narrow evolved physiological range (Pontzer, 2015a, b; Pontzer et al., 2016). The constrained total energy expenditure model contends that the addition of further physical activity, with associated additional energy costs, to individuals who are already moderately active does not result in increased total energy expenditure. This is achieved through a redistribution of energy away from other biological functions.

The allocation of limited energy and resources between physiological functions is described by life history theory (Leonard, 2012; Leonard \& Ulijaszek, 2002; Stearns, 1989; Ulijaszek, 1995; Wells et al., 2017; Zera \& Harshman, 2001). When an individual encounters an energetic deficit, such as during periods of limited food availability or when energy demands unexpectedly increase, life history theory contends that trade-offs arise in the energetic allocation between 

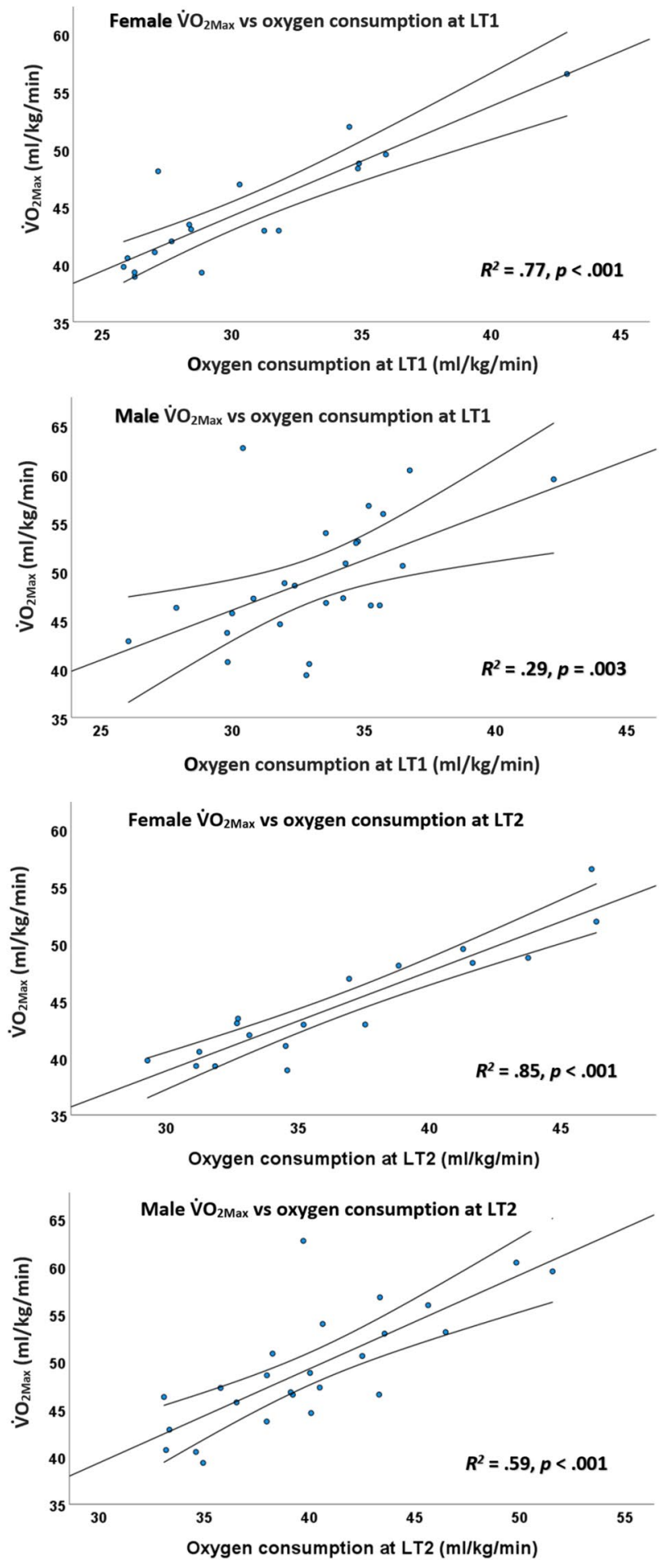
competing processes (Bronson, 1991; Stearns, 1992). In such conditions, energy is expected to be allocated towards processes offering the greatest immediate survival value. For example, the prioritisation of immune function over reproduction (Longman, Prall, et al., 2017) and growth (Urlacher et al., 2018) has been reported. A large runner adopting the low-economy high-energy turnover approach to endurance running experiences a greater metabolic burden, which may in turn push physiological functions to the limits of adaptive plasticity (Longman et al., 2020).

This increased metabolic turnover may also be detrimental in the long term. Reactive oxygen species (ROS) are by-products of aerobic metabolism, and induce pathology via oxidative stress by damaging proteins, lipids and DNA (Cross et al., 1987; Schieber \& Chandel, 2014). The generation of harmful ROS, and the associated physiological response to protect against oxidative stress, is a key determinant of longevity (Finkel \& Holbrook, 2000). A recent analysis of the life expectancy of elite athletes found that, independent of weight, high jumpers and marathon runners outlived sprinters and discus throwers (Lee-Heidenreich et al., 2017). Although further work is clearly needed, our results suggest that the higher rates of oxygen turnover associated with a larger lean body mass may partially explain the observed decreased longevity.

It is appreciated that numerous factors affecting both $\mathrm{RE}$ and $\mathrm{VO}_{2 \mathrm{Max}}$, including training status, body composition and morphology, age and running technique (see (Morgan et al., 1989; Saunders et al., 2004) for a detailed discussion) were not controlled for in this study. Finally, we acknowledge that the sample size of this study was small, and the findings will require confirmation with a larger sample.

To conclude, we observed a strong negative relationship between $\mathrm{VO}_{2 \mathrm{Max}}$ and $\mathrm{RE}$ in a cohort of ultra-endurance athletes. This relationship suggests that our hominin ancestors may have been able to occupy the behavioural niche of endurance running irrespective of their body mass by adopting different metabolic approaches. Specifically, larger individuals may have been able to compensate for low running economy by burning more energy. However, this approach may incur costs as energy may be drawn away from other biological functions, potentially including homeostatic maintenance.

Funding European Research Council under the European Union's Seventh Framework Programme, Grant/Award Number: (FP/ 2007-2013)/ERC Grant Agreement n.617627 to JTS.

Data Availability The datasets generated and analysed during the current study are available from the corresponding author upon reasonable request.

\section{Declarations}

Conflict of Interest On behalf of all authors, the corresponding author states that there is no conflict of interest.

Open Access This article is licensed under a Creative Commons Attribution 4.0 International License, which permits use, sharing, adaptation, distribution and reproduction in any medium or format, as long as 
you give appropriate credit to the original author(s) and the source, provide a link to the Creative Commons licence, and indicate if changes were made. The images or other third party material in this article are included in the article's Creative Commons licence, unless indicated otherwise in a credit line to the material. If material is not included in the article's Creative Commons licence and your intended use is not permitted by statutory regulation or exceeds the permitted use, you will need to obtain permission directly from the copyright holder. To view a copy of this licence, visit http://creativecommons.org/licen ses/by/4.0/.

\section{References}

Ackerman, J., \& Seipel, J. (2016). Effects of independently altering body weight and mass on the energetic cost of a human running model. Journal of Biomechanics, 49(5), 691-697. https://doi. org/10.1016/j.jbiomech.2016.01.016

Anderson, T. (1996). Biomechanics and running economy. Sports Medicine, 22(2), 76-89

Atkinson, G., Davison, R., Passfield, L., Nevill, A., Lucia, A., Hoyos, J. ... Chicharro, J. (2003). Could the correlation between maximal oxygen uptake and "economy" be spurious? Medicine and Science in Sports and Exercise, 35(7), 1242-1244. https://doi.org/10.1249/01.MSS.00000 $74560.08128 .5 \mathrm{D}$

Bergmann, C. (1847). Increase in the effectiveness of heat conservation in large subjects. Gottinger Studien, 3, 595-708

Boltzmann, L. (1886). Der zweite Hauptsatz der mechanischen Warmetheorie. Almanach Der Kaiserlichen Akademie Der Wissenschaften, 36, 225-259

Bourdon, P. (2000). Blood lactate transition thresholds: concepts and controversies. Physiological Tests for Elite Athletes

Bramble, D., \& Lieberman, D. (2004). Endurance running and the evolution of Homo. Nature, 432(7015), 345-352. https://doi.org/10.1038/nature03052

Bronson, F. (1991). Mammalian reproductive biology. University of Chicago Press

Bunn, H. T. (2001). Hunting, power scavenging, and butchering by Hadza foragers and by Plio-Pleistocene Homo (pp. 199-218). Meat-Eating and Human Evolution. Oxford University Press, Oxford.

Carrier, D. R. (1984). The energetic paradox of human running and hominid evolution. Current Anthropology, 25(4), 483-495

Cavanagh, P., Pollock, M., \& Landa, J. (1977). A biomechanical comparison of elite and good distance runners. Annals of the New York Academy of Sciences, 301, 328-345

Cerling, T., Harris, J., MacFadden, B., Leakey, M., Quade, J., Eisenmann, V., \& Ehleringer, J. (1997). Global vegetation change through the Miocene/Pliocene boundary. Nature, 389(6647), 153-158

Cerling, T., Levin, N., Quade, J., Wynn, J., Fox, D., Kingston, J. ... Brown, F. (2010). Comment on the paleoenvironment of ardipithecus ramidus. Science, 328(5982). https://doi.org/10.1126/science. 1185274

Crognier, E. (1981). Climate and anthropometric variations in Europe and the Mediterranean area. Annals of Human Biology, 8(2), 99-107

Cross, C., Halliwell, B., Borish, E., Pryor, W., Ames, B., Saul, R. ... Harman, D. (1987). (1987). Oxygen radicals and human disease. Annals of Internal Medicineernal Medicine, 107(4), 526-545

Dalleau, G., Belli, A., Bourdin, M., \& Lacour, J. (1998). The spring-mass model and the energy cost of treadmill running. European Journal of Applied Physiology and Occupational Physiology, 77, 257-263

Dart, R. (1925). The Man-Ape of South Africa. Nature, 115, 195-199

di Prampero, P. (2003). Factors limiting maximal performance in humans. European Journal of Applied Physiology, 90, 420-429

Epstein, Y., Stroschein, L., \& Pandolf, K. (1987). Predicting metabolic cost of running with and without backpack loads. European Journal of Applied Physiology and Occupational Physiology, 56(5), 495-500. https://doi.org/10.1007/BF00635360

Farley, C., \& McMahon, T. (1992). Energetics of walking and running: Insights from simulated reducedgravity experiments. Journal of Applied Physiology, 73(6), 2709-2712. https://doi.org/10.1152/ jappl.1992.73.6.2709 
Finkel, T., \& Holbrook, N. (2000). Oxidants, oxidative stress and the biology of ageing. Nature, 408(6809), 239-247. https://doi.org/10.1038/35041687

Fletcher, J., Esau, S., \& Macintosh, B. (2009). Economy of running: beyond the measurement of oxygen uptake. Journal of Applied Physiology, 17, 1918-1922. https://doi.org/10.1152/japplphysiol.00307. 2009

Foster, F., \& Collard, M. (2013). A reassessment of Bergmann's Rule in modern humans. PLOS ONE, 8(8), e72269. https://doi.org/10.1371/journal.pone.0072269

Gordon, D., Wightman, S., Basevitch, I., Johnstone, J., Espejo-Sanchez, C., Beckford, C. ... Merzbach, V. (2017). Physiological and training characteristics of recreational marathon runners. Open Access Journal of Sports Medicineournal of Sports Medicine, 8, 231

Haile-Selassie, Y. (2001). Late Miocene hominids from the middle Awash, Ethiopia. Nature, 412(6843), 178-181

Heglund, N., \& Taylor, C. (1988). Speed, stride frequency and energy cost per stride: how do they change with body size and gait? Journal of Experimental Biology, 138, 301-318

Hiernaux, J. (1968). La diversity humaine en Afrique subsaharienne. Editions de l'Institut de Sociologie, Universite Libre de Bruxelles, Belgium.

Hiernaux, J., \& Fromont, A. (1976). The correlations between anthropobiological and climatic variables in sub-Saharan Africa: revised estimates. Human Biology, 757-767

Holliday, T., \& Trinkaus, E. (1991). Limb/trunk proportions in Neandertals and early anatomically modern humans. American Journal of Physical Anthropology, 12, 93-94

Holliday, T. (1997). Body proportions in Late Pleistocene Europe and modern human origins. Journal of Human Evolution, 32, 423-447

Holliday, T. (1997b). Postcranial evidence of cold adaptations in European Neanderthals. American Journal of Physical Anthropology, 104(May 1996), 245-258

Holloszy, J., Rennie, M., Hickson, R., Conlee, R., \& Hagberg, J. (1977). Physiological consequences of the biochemical adaptations to endurance exercise. Annals of the New York Academy of Sciences, $301,440-450$

Ingham, S., Whyte, G., Pedlar, C., Bailey, D., Dunman, N., \& Nevill, A. (2008). Determinants of 800-m and 1500-m running performance using allometric models. Medicine \& Science in Sports \& Exercise, 40(2), 345-350

Joyner, M. (1991). Modeling: optimal marathon performance on the basis of physiological factors. Journal of Applied Physiology, 70(2), 683-687

Katzmarzyk, P., \& Leonard, W. (1998). Climatic influences on human body size and proportions: ecological adaptations and secular trends. American Journal of Physical Anthropology, 503, 483-503. https://doi.org/10.1002/(SICI)1096-8644(199808)106

Ker, R. (1987). The spring in the arch of the human foot. Nature, 325, 147-149

Kram, R., \& Taylor, C. (1990). Energetics of running: a new perspective. Nature, 346, 265-267. https:// doi.org/10.1017/CBO9781107415324.004

Lee-Heidenreich, J., Lee-Heidenreich, D., \& Myers, J. (2017). Differences in life expectancy between olympic high jumpers, discus throwers, marathon and 100 meter runners. BMC Sports Science, Medicine and Rehabilitation, 9(1), 1-6. https://doi.org/10.1186/s13102-017-0067-z

Leonard, W. R., \& Ulijaszek, S. J. (2002). Energetics and evolution: an emerging research domain. American Journal of Human Biology, 550, 547-550

Leonard, W. R. (2012). Laboratory and field methods for measuring human energy expenditure. American Journal of Human Biology, 24(3), 372-384. https://doi.org/10.1002/ajhb.22260

Lieberman, D., Bramble, D., Raichlen, D., \& Shea, J. (2006). Brains, brawn, and the evolution of human endurance running capabilities. In E.Grine, F., \& Fleagle, J. G., Richard,E.Leakey (Eds.), The First Humans - Origin and Early Evolution of the Genus Homo. Springer

Lieberman, D., \& Bramble, D. (2007). The evolution of marathon running. Sports Medicine, 37, 288-290

Lieberman, D. (2010). Four legs good, two legs fortuitous: brains, brawn, and the evolution of human bipedalism. In J. LOSOS (Ed.), In the Light of Evolution (2ND ed., pp. 55-71). Roberts and Company

Lieberman, D. E. (2012a). Those feet in ancient times. Nature, 483(7391), 550-551.

Lieberman, D. (2012b). What can we learn about running from barefoot running: An evolutionary medical perspective. Exercise and Sport Sciences Reviews, 40(2), 63-72

Lieberman, D. (2015). Human locomotion and heat loss: An evolutionary perspective. Comprehensive Physiology, 5(1), 99-117. https://doi.org/10.1002/cphy.c140011

Lodge, O. (1906). Life and Matter 
Longman, D., Wells, J., \& Stock, J. (2015). Can persistence hunting signal male quality? A test considering digit ratio in endurance athletes. Plos One, 10(4), e0121560

Longman, D., Prall, S., Shattuck, E., Stephen, I., Stock, J., Wells, J., \& Muehlenbein, M. (2017a). Shortterm resource allocation during extensive athletic competition. American Journal of Human Biology, 30(1). https://doi.org/10.1002/ajhb.23052

Longman, D., Stock, J., \& Wells, J. (2017b). A trade-off between cognitive and physical performance, with relative preservation of brain function. Scientific Reports, 7(1). https://doi.org/10.1038/ s41598-017-14186-2

Longman, D., Surbey, M., Stock, J., \& Wells, J. (2018). Tandem androgenic and psychological shifts in male reproductive effort following a manipulated "Win" or "Loss" in a sporting competition. Human Nature, 29(3), 283-310. https://doi.org/10.1007/s12110-018-9323-5

Longman, D., Macintosh, A., Roberts, R., Oakley, S., Wells, J., \& Stock, J. (2019). Ultra-endurance athletic performance suggests energetics drive human morphological thermal adaptation. Evolutionary Human Sciences, 1 , e16

Longman, D., Wells, J., \& Stock, J. (2020). Human athletic paleobiology; using sport as a model to investigate human evolutionary adaptation, (December 2019), 1-18. https://doi.org/10.1002/ajpa.23992

Longman, D., Murray, A., Roberts, R., Oakley, S., Wells, J., \& Stock, J. (2021). Energetics as a driver of human morphological thermal adaptation; evidence from female ultra-endurance athletes. Evolutionary Human Sciences, 3, e22

Lotka, J. (1922). Contribution to the energetics of evolution. Proceedings of the National Academy of Sciences of the United States of America, 8, 147-151

Lucia, A., Hoyos, J., Perez, M., Santalla, A., \& Chicharro, J. (2002). Inverse relationship between VO2 Max and economy / efficiency in world-class cyclists. Medicine \& Science in Sports \& Exercise, 2079-2084. https://doi.org/10.1249/01.MSS.0000039306.92778.DF

Maldonado-Martin, S., \& Padilla, S. (2002). Influence of body mass and height on the energy cost of running in highly trained middle- and long-distance runners. International Journal of Sports Medicine, 23(04), 268-272. https://doi.org/10.1055/s-2002-29083

McLaughlin, J., Howley, E., Bassett, D., Thompson, D., \& Fitzhugh, E. (2010). Test of the classic model for predicting endurance running performance. Medicine \& Science in Sports \& Exercise, 42(5), 991-997

Minetti, A. E. (2003). Efficiency of equine express postal systems. Nature, 426(December), 785-786

Morgan, D., Martin, P., \& Krahenbuhl, G. (1989). Factors affecting running economy. Sports Medicine, 7(5), 310-330

Morgan, D., \& Daniels, J. (1994). Relationship between VO2max and the aerobic demand of running in elite distance runners. International Journal of Sports Medicine, 15(7), 426-429

Napier, J. (1967). The antiquity of human walking. Scientific American, 216(4), 56-67

Pate, R., Macera, C., Bailey, S., Bartoli, W., \& Powell, K. (1992). Physiological, anthropometric, and training correlates of running economy. Medicine and Science in Sports and Exercise, 24(10), 1128-1133

Pontzer, H., Raichlen, D., \& Sockol, M. (2009). The metabolic cost of walking in humans, chimpanzees, and early hominins. Journal of Human Evolution, 56(1), 43-54. https://doi.org/10.1016/j.jhevol.2008. 09.001

Pontzer, H. (2015). Constrained total energy expenditure and the evolutionary biology of energy balance. Exercise and Sport Sciences Reviews, 43(3), 110-116. https://doi.org/10.1249/JES.0000000000000048

Pontzer, H. (2015). Energy expenditure in humans and other primates: a new synthesis. Annual Review of Anthropology, 44, 169-187. https://doi.org/10.1146/annurev-anthro-102214-013925

Pontzer, H., Durazo-Arvizu, R., Dugas, L., Plange-Rhule, Bovet, P., Forrester, T. ... Luke, A. (2016). Constrained total energy expenditure and metabolic adaptation to physical activity in adult humans. Current Biology, 26(3), 410-417

Roberts, D. (1953). Body weight, race and climate. American Journal of Physical Anthropology, 11(4), 533-558

Roberts, T. J., Kram, R. O. D. G. E. R., Weyand, P. G., \& Taylor, C. R. (1998). Energetics of bipedal running. I. Metabolic cost of generating force. The Journal of experimental biology, 201(19), 2745-2751.

Rodman, P., \& McHenry, H. (1980). Bioenergetics and the origin of human bipedalism. American Journal of Physical Anthropology, 52, 103-106

Rogers, I. (2003). The influence of birthweight and intrauterine environment on adiposity and fat distribution in later life. International Journal of Obesity, 27(7), 755-777. https://doi.org/10.1038/sj.ijo.0802316

Ruff, C. (1994). Morphological adaptation to climate in modern and fossil hominoids. Yearbook of Physical Anthropology, 37, 65-107 
Santalla, A., Naranjo, J., \& Terrados, N. (2009). Muscle efficiency improves over time in world-class cyclists. Medicine \& Science in Sports \& Exercise, 41(5), 1096-1101

Saunders, P., Pyne, D., Telford, R., \& Hawley, J. (2004). Factors affecting running economy in trained distance runners. Sports Medicine, 34(7), 465-485. https://doi.org/10.2165/00007256-200434070-00005

Schieber, M., \& Chandel, N. (2014). ROS function in redox signaling and oxidative stress. Current Biology, 24(10), R453-R462. https://doi.org/10.1016/j.cub.2014.03.034

Senut, B., \& Pickford, M. (2004). La dichotomie grands singes-homme revisitée. Comptes Rendus Palevol, 3(4), 265-276. https://doi.org/10.1016/j.crpv.2003.12.005

Serrat, M., King, D., \& Lovejoy, C. (2008). Temperature regulates limb length in homeotherms by directly modulating cartilage growth. Proceedings of the National Academy of Sciences, 105(49), 19348-19353. https://doi.org/10.1073/pnas.0803319105

Shaw, A., Ingham, S., Atkinson, G., \& Folland, J. (2015). The correlation between running economy and maximal oxygen uptake: Cross-sectional and longitudinal relationships in highly trained distance runners. PLoS ONE, 10(4), 1-10. https://doi.org/10.1371/journal.pone.0123101

Sockol, M., Raichlen, D., \& Pontzer, H. (2007). Chimpanzee locomotor energetics and the origin of human bipedalism. Proceedings of the National Academy of Sciences of the United States of America, 104(30), 12265-12269. https://doi.org/10.1073/pnas.0703267104

Stearns, S. (1989). Trade-Offs in life-history evolution. British Ecological Society, 3, 259-268

Stearns, S. (1992). The evolution of life histories. Oxford University Press

Stinson, S. (1990). South American Indians. American Journal of Human Biology, 2, 37-51

Taylor, C., Heglund, N., McMahon, T., \& Looney, T. (1980). Energetic cost of generating muscular force during running: a comparison of large and small animals. Journal of Experimental Biology, 86(1), 9-18. https://doi.org/10.1242/jeb.86.1.9

Te Velde, S., Twisk, J., Van Mechelen, W., \& Kemper, H. (2003). Birth weight, adult body composition, and subcutaneous fat distribution. Obesity Research, 11(2), 202-208. https://doi.org/10.1038/oby.2003.32

Teunissen, L., Grabowski, A., \& Kram, R. (2007). Effects of independently altering body weight and body mass on the metabolic cost of running. Journal of Experimental Biology, 210(24), 4418-4427. https:// doi.org/10.1242/jeb.004481

Tilkens, M., Wall-Scheffler, C., Weaver, T., \& Steudel-Numbers, K. (2007). The effects of body proportions on thermoregulation: an experimental assessment of Allen's rule. Journal of Human Evolution, 53(3), 286-291. https://doi.org/10.1016/j.jhevol.2007.04.005

Trinkaus, E. (1981). Neanderthal limb proportions and cold adaptation. In C. Stringer (Ed.), Aspects of Human Evolution (pp. 187-224). Taylor \& Francis

Ulijaszek, S. J. (1995). Human energetics in biological anthropology. Cambridge University Press

Urlacher, S., Ellison, P., Sugiyama, L., Pontzer, H., Eick, G., Liebert, M. .. Snodgrass, J. (2018). Tradeoffs between immune function and childhood growth among Amazonian forager-horticulturalists. Proceedings of the National Academy of Sciences of the United States of America, 115(17), E3914-E3921. https://doi.org/10.1073/pnas.1717522115

Wells, J., Nesse, R., Sear, R., Johnstone, R., \& Stearns, S. (2017). Evolutionary public health: introducing the concept. The Lancet, 390(10093), 500-509. https://doi.org/10.1016/S0140-6736(17)30572-X

Wells, J., Saunders, M., Lea, A., Cortina-Borja, M., \& Shirley, M. (2019). Beyond Bergmann's rule: Global variability in human body composition is associated with annual average precipitation and annual temperature volatility. American Journal of Physical Anthropology, 170, 75-87. https://doi.org/10.1002/ ajpa. 23890

Will, M., \& Stock, J. (2015). Spatial and temporal variation of body size among early Homo. Journal of Human Evolution, 82, 15-33. https://doi.org/10.1016/j.jhevol.2015.02.009

Will, M., Pablos, A., \& Stock, J. T. (2017). Long-term patterns of body mass and stature evolution within the hominin lineage. Royal Society open science, 4(11), 171339.

Will, M., Krapp, M., Stock, J., \& Manica, A. (2021). Different environmental variables predict body and brain size evolution in Homo. Nature Communications, 12(1), 1-12. https://doi.org/10.1038/ s41467-021-24290-7

Williams, K., \& Cavanagh, P. (1985). Relationship between distance running mechanics, running economy, and performance. Journal of Applied Physiology, 63, 1236-1245

Wright, S., \& Weyand, P. G. (2001). The application of ground force explains the energetic cost of running backward and forward. The Journal of Experimental Biology, 204, 1805-1815

Zera, A. J., \& Harshman, L. G. (2001). The physiology of life history trade-offs in animals. Ecology, 32, 95-126 
Zihlman, A., \& Brunker, L. (1979). Hominin Bipedalism; Then and Now. Yearbook of Physical Anthropology, 22, 132-162

Publisher's Note Springer Nature remains neutral with regard to jurisdictional claims in published maps and institutional affiliations.

\section{Authors and Affiliations}

Daniel P. Longman ${ }^{1}$ (D) Viviane Merzbach ${ }^{2}$ (D) Jorge Marques Pinto ${ }^{2}$. Laura Hope Atkinson ${ }^{3}$ (D) . Jonathan C. K. Wells ${ }^{4}$. Dan Gordon ${ }^{2}$ (D) . Jay T. Stock ${ }^{3,5}$ (D)

Daniel P. Longman

D.Longman@lboro.ac.uk

$\bowtie$ Dan Gordon

$\triangle$ Jay T. Stock

1 School of Sport, Exercise and Health Sciences, Loughborough University, LE11 3TU Loughborough, UK

2 Cambridge Centre for Sport \& Exercise Sciences, Anglia Ruskin University, Cambridge CB1 1PT, UK

3 Department of Anthropology, University of Western Ontario, London, Ontario, Canada

4 Childhood Nutrition Research Centre, UCL Institute of Child Health, WC1N 1EH London, UK

5 Department of Archaeology, Max Planck Institute for the Science of Human History, Kahlaische Strasse 10, D-07745 Jena, Germany 